Paediatric Psychology

\title{
Social Ecological Approach to Sexting Behaviour
}

\author{
Arta Dodaj ${ }^{1 a}$, Kristina Sesar ${ }^{2 b}$ \\ ${ }^{1}$ Department of Psychology, University of Zadar, Zadar, Croatia, ${ }^{2}$ Department of Psychology, University of Mostar, Mostar, \\ Bosnia and Herzegovina \\ Correspondence: artadodaj@gmail.com; Tel.: + 38598 8001 87; Fax.: + 38523200625
}

Received: July 19, 2021; Accepted: September 22, 2021

\begin{abstract}
Objective - The aim of this paper was to collect and summarize findings regarding the factors associated with sexting experiences and their correlates, under Bronfenbrenner's socio-ecological theory. Methods - We reviewed the literature in the field of sexting to show how numerous factors that have been found to influence sexting behaviour can be included within a social-ecological framework. Electronic literature searches were conducted between May and June 2021 in the following databases: EbscoHOST (PsycINFO, PSychArticles), ERIC, Google Scholar, ResearchGate, ScienceDirect, SCOPUS, and Web of Science. Conclusion - This model seems to be a good framework for systematizing the results of research in this area, and can be used as a guide for future research on sexting. We encourage researchers to expand or redefine the proposed determinants of sexting in a theoretically more satisfactory way, as well as to explore it empirically. To help youth avoid the negative consequences of engaging in potentially harmful sexting behaviours, the multiple systems that surround young people should work together to provide young people with the skills necessary to make good choices about their sexual behaviours.
\end{abstract}

Key Words: Sexting - Socio-Ecological Model - Technology • Youth.

\section{Introduction}

Over the past decade, sexting among youth has become an issue that permeates psychological studies across many fields $(1,2)$. Researchers have increasingly sought to explore the various risk and protective factors associated with sexting experiences (3). More recently, the proliferation of information and communication technologies has led researchers, policy makers, and educators to examine the changing environment and context of sexting among youth.

Despite the many benefits of the Internet, such as social interaction and communication, there are risks and consequences involved in sexting, especially the negative aspects of sexting in various

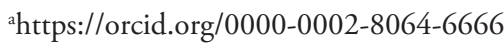

bhttps://orcid.org/0000-0003-2406-7114 functional areas (e.g., psychological, behavioral, and social functioning) (4). There is neither a single, universally accepted definition of sexting, nor a strong theoretical perspective to understand this phenomenon. Existing definitions suggest that sexting is a behavior related to sending, receiving and posting sexually explicit messages, photos, and videos (whether one's own half-naked/nude photos/ videos or someone else's photos/videos) via a cell phone, e-mail, Internet, or Social Networking Service (5). Moreover, sexting can be understood as a multidimensional phenomenon that encompasses different types, depending on the harmful effects $(6,7)$ or the motives for sexting $(4)$.

Wolak and Finkelhor (8) divided sexting into two categories, which they termed 'Aggravated' and 'Experimental'. Aggravated sexting incidents included criminal or abusive elements beyond creat- 
ing, sending, or possessing sexual images produced by the young people themselves. These additional elements included: 1) adult involvement or 2) criminal or abusive behavior by minors, such as sexual abuse, extortion, threats and malicious behavior due to an interpersonal conflict, or creating, sending, or showing images without the knowledge or against the will of the minor depicted. In the experimental sexting incidents, adolescents took pictures of themselves to send to established boyfriends or girlfriends on the basis of romantic interest in other adolescents, or for reasons such as attention seeking, but there was no criminal behavior beyond creating or sending pictures, no apparent malice, and no unwillingness on the part of the imaged adolescents to participate. Dodaj and Sesar (9) proposed that sexting behavior takes four forms: relational sexting, reactive sexting, coercive sexting, and violent sexting. The authors define this operationalization of sexting by focusing on the motivation for sexting and the underlying sexting elements (such as the content of sexts, etc.). A further distinction can be made between primary sexting (sending and receiving), where sexual content is usually shared consensually among peers and not sent to anyone else (except in cases of peer pressure, sextortion...), and secondary sexting (forwarding and receiving through an intermediary), when someone shares sexual content beyond the intended recipient, often non-consensually (10).

There are two different ways of "understanding" sexting in the literature. Some authors describe sexting as a modern form of intimate communication between young people (11). According to them, sexting is a normative behaviour for youth (12) or represents the consensual production and dissemination of sexual content important for pleasure, sexual identity, relationships, etc. (13). Other researchers believe that sexting is associated with certain risk factors, but also with negative consequences. Sexting is sometimes used as a means of blackmailing young people (14), or even as a means of revenge against ex-partners (15).

Initial research on sexting attempted to explain it within the framework of theories of aggression, such as criminological theories of criminal behaviour or social learning theories of aggressive behaviour. However, as no single theory has been able to provide a satisfactory explanation for this complex phenomenon, more complex and comprehensive integrative models have recently been developed that take into account both the deviant perspective of sexting and the normal perspective of sexting (16).

Bronfenbrenner's social-ecological model (17) was first introduced as a conceptual model for understanding human development, and later formalized as a theory. This model can provide a holistic approach to sexting because it places the individual at the centre, surrounded by various systems. The socio-ecological perspective has been used to understand the risk and protective factors for risky behaviours in online environments, such as cyberbullying (18). We believe that there is no single factor that can explain why some youth are at a higher risk of engaging in sexting than others. A person's risk of exposure to sexting is determined by factors from the young person's social environment, such as at home, at school, or in the wider community. Researchers studying sexting have rarely acknowledged this framework. This holistic framework focuses on understanding how individual characteristics of youth interact with the environment to promote or inhibit behaviour. According to this model, all behaviour can be explained by risk factors in several systems that surround an individual and have a direct or indirect influence on the person's behaviour. In addition to these systems, individual factors, i.e., biological factors, personal history, alcohol/drug use, and attitudes, also influence a particular behaviour. The individual's relationships with family, friends, peers, teachers, and others in the individual's immediate environment represent microsystem factors that directly affect behaviour. The interactions of the microsystems of family, school, and peers form a mesosystem that also has a direct influence on the occurrence of a particular behaviour. In addition to direct influences, systems such as social communities, neighbourhoods, and the media (exosystem), as well as culture and politics (macrosystem), have an indirect influence on the oc- 


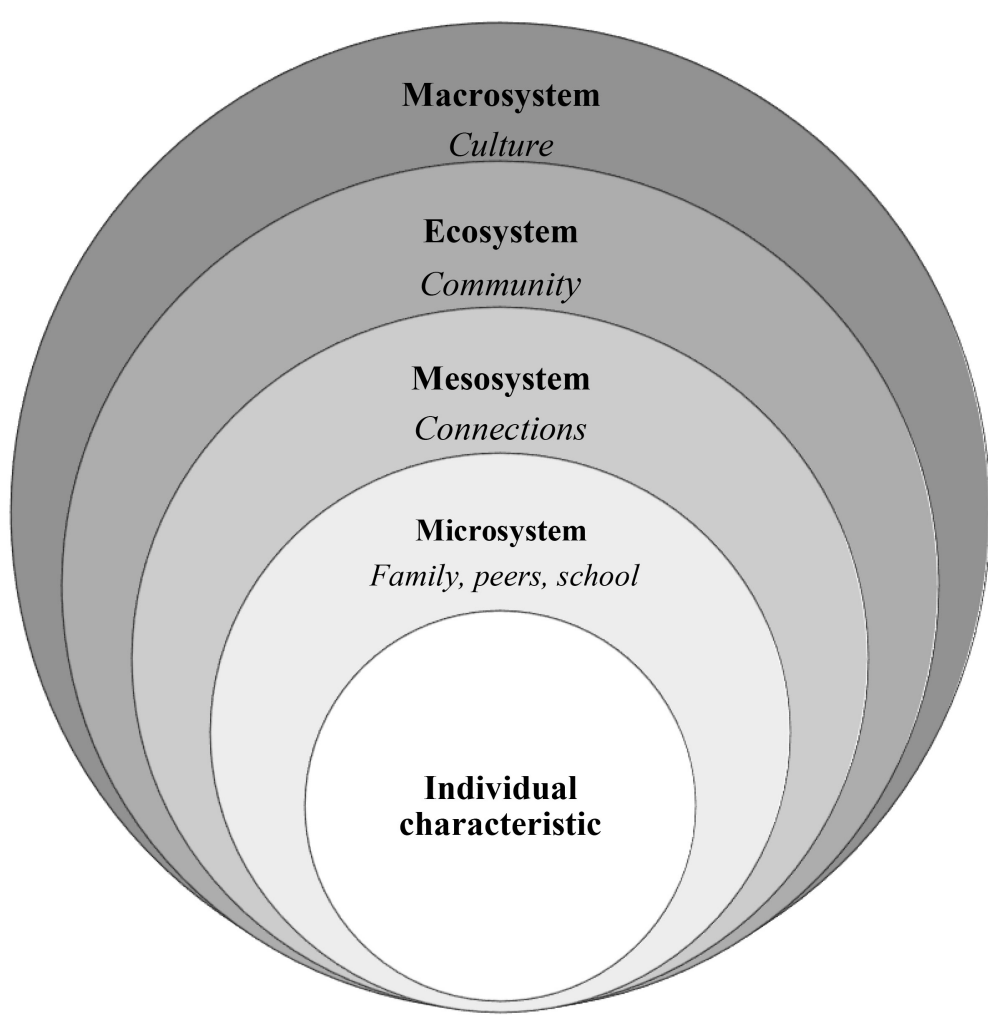

Fig. 1. A socio-ecological framework of sexting.
ERIC, Google Scholar, ResearchGate, ScienceDirect, SCOPUS, and Web of Science. The search included the use of the following terms in the title, abstract, and keywords: sext, sexting, sex texting, sexual messaging, sexto, sharing sexually explicit media, consensual sexting, nonconsensual sexting, non-consensual pornography, primary sexting, revenge porn, unwanted sexting, pressured sexting, unpressured sexting, sext dissemination, solicited sext, unsolicited sext, sending sexually explicit images, videos, and/or messages, receiving sexually explicit images, videos, and/or messages, forwarding sexually explicit images, videos, and/or messages, posting sexually explicit images, videos, and/or messages, blackmailing sexually explicit images, videos, and/ or messages, cybergossip, cybersex, sextortion, technology mediated sexual violence, technology mediated sexual harassment, sexual harassment, and erotic extortion. We extracted data from original peer-reviewed scientific and theoretical articles published between 2004 and 2021 that focused on factors associated with different types of sexting behaviours that can be classified under the assumption of a social-ecological approach. Of the peer-reviewed articles, 80 articles that met the inclusion criteria were selected and reviewed.

\section{Individual Determinants of Sexting}

The social-ecological model has only been tested using some individual or relational factors. For example, at the individual level, demographic attributes related to gender are the most researched variable. Earlier studies showed that boys are more prone to sexting (20), while recent national studies (22), as well as a meta-analysis (23), showed no sex differences. 
The findings on the relationship between age and sexting among youth are consistent and show that sexting participation increases with age (20, 26-28), which can be explained by increasing sexual interest and exploration with age (16). This supports the view that sexting is a normal part of sexual development (23). Further, sexting has been linked to emotional dysregulation (29-31), a tendency to risky sexual behaviour (32-35), substance/alcohol abuse (26, 32-39), and aggressive behaviour (26, $37)$. Results indicate that youth with certain personality traits are more prone to sexting, such as sensation-seeking (34, 40-42), impulsivity-related personality traits $(34,39)$, histrionic personality tendency (36), and extroversion (43-47). Internalized emotional problems, such as depression and anxiety, also play an important role in sexting (2628, 42, 48-58). Further, studies have identified the risk of attempting suicide in all sexting participants $(26,56)$. It is likely that sexting and psychosocial correlates may be partially relevant for those who participate in non-consensual or pressured sexting.

Attitudes and beliefs about sexting have been shown to be good predictors of sexting (20,36-37, 57-58). Those who participate in sexting consider it to be the most common pattern of behaviour in imitating or maintaining an intimate relationship, exploring their identity, or having fun or gaining popularity among peers $(24,34,56)$. Personality domains, such as impulsivity or histrionic traits, may be associated with sexting in that they are related to positive sexting attitudes.

It can be concluded that many individual traits, the characteristics that make youth stand out as different in appearance or affiliation, or extremely vulnerable (anxiety, depression), are risk factors for sexting. On the other hand, those characteristics that make them susceptible to socially undesirable behaviours (sexually risky behaviour, substance abuse) encourage them to continue their sexting behaviour.

\section{Microsystems and Sexting: Family, Peers and School}

According to Bronfenbrenner's model (17), a microsystem includes all the environmental factors of development with which the person is in direct interaction, and which have a direct influence on the individual's development. The most important factors of microsystems are family, peers, and school.

\section{Family}

The family is our primary environment in which we grow up, and it plays a key role in various aspects of our development. Few studies to date have examined the role of aspects of parental behaviour in sexting. Communication between parents and youth who participate in sexting is disrupted. In general, poor family communication increases the likelihood that youth will engage in sexting (48, 59). Burić, Garcia and Štulhofer (48) found in a sample of Croatian adolescents that a family environment characterised by intense quarrels, aggressive behaviour and ignoring family members was related to more frequent sexting among young people. A study conducted among Canadian adolescents revealed that better parent-child communication predicted less sending of sexually explicit images (60). Compatible findings were obtained from an Italian sample of female adolescents (59), where poor family communication significantly predicted sexting in general, as well as risky sexting (for emotion regulation and sharing sexts with large numbers of people). Thus, the authors found that experimental sexting (exchanging sexts with a partner) was significantly predicted by family flexibility, and aggravated sexting (non-consensual forwarding of sexts) was predicted by family enmeshment. Parents who demonstrate flexibility may have more communication with their children, including sexual communication, as a motivation to contribute to their well-adjusted behaviour.

The findings of research on the impact of parental control on sexting are not consistent. For example, Campbell and Park's (61) study of a sample of U.S. adolescents found that strict parental control over technology did not contribute to less sexting, whereas family connectedness using mobile phones did. West et al.'s (62) study among Peruvian adolescents showed that parents sharing clear rules about 
sexting was only effective in its reduction among boys. For both boys and girls, their parents' negative attitudes toward adolescent sexual relationships had a significant impact on reducing sexting. Data obtained among adolescents in Croatia (63) and Israel (64) revealed that lower parental control increased the adolescent's likelihood of sexting. Finally, examining parental supervision of adolescent cell phone use, Lenhart (65) found a lower frequency of sending sexually explicit content or photos in situations where parents restricted cell phone use.

The quality of emotional attachment with parents is an important factor in relationships with others throughout life, and thus affects sexting behaviour. Research shows that adolescents who are more likely to ask someone else to send nude or semi-nude photos have a more permissive attachment style to their parents (64). Results also revealed that better parent-child communication was predictive of a lower frequency of adolescents sending sexual images, and that a report of greater adolescent attachment avoidance was predictive of a higher frequency of adolescents sending sexual images. Although parental warmth and parental psychological control did not directly predict adolescents sending sexual images, these variables were found to have indirect effects on sending sexual images through attachment avoidance. These findings suggest that parent-child communication has a relatively stronger, more direct relationship with adolescents sending sexual images, but that parental warmth and psychological control may also influence this behaviour through the formation of adolescents' working models of relationships (60). Parents with insecure attachment styles do not develop closeness and trust with others, including their children. Therefore, when children engage in sexual experimentation through sexting, which could also be a risky behaviour, they could be filling their emotional gaps.

\section{Peers}

Belonging to peer groups is very important during adolescence. Youth are more likely to sext if they feel that their peers approve sexting (57) and have positive attitudes toward sexting (66-67). They are also more likely to sext if they have positive attitudes toward peers who sext (58). Some youth who are popular enforce their own values of sexting as tolerated and normative for the group, thereby increasing the likelihood of sexting by others (68). Under the impression of normative behaviour, youth may engage in sexting and obtain peer acceptance and attention. A review by Sesar, Dodaj and Šimić (16) suggests that no other form of potentially risky behaviour in youth exerts as much peer pressure on youth as sexting.

\section{School}

School is an important microsystem in which children interact with teachers and peers, not only to acquire formal knowledge, but also to form an image of themselves and the world in which they live. Perceived "belonging" at school is a protective element within the school context that has been widely researched in scholarship on adolescent behaviours (69). The prevalence of sexting in school could be related to the extent to which young people identify or bond with their school. Attachment to school could play a critical role in inhibiting young people's motivation to engage in risky behaviours, as research has shown (70-71). Not only sexting, but other types of risky sexual behaviours are less common among youth who report attachment to school (72). Hunter et al. (73) found that school connectedness was significantly and negatively associated with passive sexting but not active sexting. According to King et al. (74), school connectedness can be improved, and such interventions can help reduce the extent to which young people are asked to sext and have unsolicited sexting sent to them. However, Hunter et al.'s (73) research findings are less supportive of the possibility that improvements in school connectedness could reduce more active sexting behaviours (e.g. sending sexts). In addition, Walrave et al. (75) found that the extent to which adolescents believe their teachers would approve of sexting, and whether they attach importance to 
their teachers' opinions about sexting, did not predict adolescents' sexting intentions. A second schoollevel contextual variable is the extent to which a school explicitly provides education and support to students regarding positive interactions (73).

\section{Mesosystem and Sexting}

The interactions between microsystems form a mesosystem that also has a direct impact on the experience of sexting behaviour among youth. Although many researchers (76) emphasize the importance of parent-teacher collaboration and parental involvement in the lives of children and youth to prevent sexting, there is a lack of research on the relationship between these factors and sexting. Parental involvement in the school system and collaboration with the school can play an important role in preventing the negative consequences of sexting. In addition, especially for older parents, parental knowledge about technology and its impact on youth can play an important role in understanding sexting. For example, schools can organize lectures about Internet safety or provide information about sexting behaviour through school magazines, brochures, or school websites (77-79). Furthermore, it seems important to examine family-peer interaction in order to act successfully in the direction of prevention. Parents should be interested in their children's lives, and be familiar with their children's friends and their families.

\section{The Exosystem and Sexting}

The exosystem refers to the forces within the larger social system in which the individual is embedded, but the individual has no active role within these larger systems (17). These factors include the judicial and police systems, sex education, public awareness, and community influences. Sex education in the school system is a factor within the exosystem (80). Sex education focuses on promoting safer sex rather than abstaining from sexual activity, and provides adolescents with information on how to practise safer sex, and thus can influence adolescents' sexual behaviour (81). For example, attitudes towards sexuality among adolescents in Sweden have been found to be relatively liberal compared to other Western countries (82).

Educational initiatives on sexting or 'sext education' (83), carried out as part of cyber safety campaigns, turn schools into places where sex and gender norms are policed. Many of these initiatives target girls and imply that they are responsible for minimising sexting risks (e.g. revenge porn) (84). Therefore, researchers (85-86) have called for educational initiatives that not only minimise the negative consequences of sexting, but also challenge (rather than reproduce) gender double standards, and pay more attention to young people's opinions when educating them about sexting.

Living in a community with high levels of sexualized popular culture provides an opportunity for children and young people to explore sexuality, as well as the opportunity to share sexually explicit content through the media (87). Some authors $(21,24,87-88)$ state that in the context of a markedly sexual consumer culture, which is dominant in contemporary society, sexting is part of the integral sexual behaviour of young people. Daily exposure to sexuality in the media may change young people's attitudes towards sexting and reduce their sensitivity to the negative consequences of sexting behaviour. They can become more aware of the importance of exploring their sexuality and being more expressive of their sexual needs and desires.

Awareness of the potential legal and other negative consequences of sexting can influence the prevalence and motivation for sexting. According to the study by Strohmaier et al. (89) young people who, as minors, are aware of the legal consequences of sexting are significantly less likely to engage in sexting than their peers.

\section{Macrosystem and Sexting}

Temple-Smith et al. (90) state that cultural values can influence adolescent sexual development and behaviour by prescribing attitudes and norms about how adolescents' sexuality should be viewed and how they should behave. Unfair and contradictory 
double sexual standards and different sexual norms for boys and girls are found in Western culture (91). These norms mean that girls' sexual behaviour is shamed and stigmatized, while boys' sexual behaviour is generally more acceptable and may even be socially rewarded (91). Family, peers and friends often perpetuate a sexual double standard (92). Alison and Risman (93) report that most adolescents do not uphold these norms and disapprove of them when asked directly. Yet, a recent study has shown that they are still upheld among adolescents (94).

Research shows a consistent trend that certain ethnic groups of adolescents are more likely to sext. Studies comparing American adolescents to non-American adolescents showed that adolescents from the United States were more likely to sext than adolescents from other countries (e.g., Belgium, China, Czech Republic, Ireland, Italy, Poland, Russia, Turkey, and/or Uganda) (95-96). A cross-cultural study conducted only in European countries showed that the highest prevalence of sexting was found in less traditional countries, such as England and Norway, in comparison to the more traditional countries studied of Bulgaria, Cyprus, and Italy (97-98). Therefore, in traditional, sexually restrictive societies, adolescent sexuality and sexting behaviour may be perceived as unacceptable (4). The moral basis with regard to sexting behaviour has not been directly examined. The National Campaign's Sex \& Tech Survey study (99) listed reasons for non-sexters' disapproval of sexting. Responses included "immoral" as a reason for not sexting, and "it goes against religious/cultural beliefs." The findings are supported by the study by Abraham (100) who found that moral foundations play a role in participation in sexting behaviours. In addition, Crimmins and Seigfried-Spellar (101) found that individuals who send nude sexts place less emphasis on purity as a moral foundation. However, their study found no significant differences between semi-nude sexting and moral foundations.

\section{Conclusion}

Sexting is a complex phenomenon that needs to be interpreted using a complex approach, such as
Bronfenbrenner's ecological model. This model seems to be a good framework for systematizing the results of research in this area. A review of the research found that most studies on sexting examined individual factors and some microsystem factors, particularly peer influence. However, studies on the factors related to the mesosystem, exosystem, or macrosystem are less common. Therefore, no study has examined factors from the different levels of the ecological model simultaneously. This is quite understandable because the implementation of research based on the ecological model is very complex and long-lasting. Considering the relationship between system levels, it seems significant to examine the interrelationship between the components of the different systems, especially moderator and mediator relationships, and to examine the degree to which various factors of the social-ecological model are separately and uniquely predictive of sexting. Further, we encourage researchers to explore and adopt this framework to provide a theoretically more satisfying approach to investigating sexting.

Authors' Contributions: Conception and design: $\mathrm{AD}$ and $\mathrm{KS}$; Acquisition of data $\mathrm{AD}$; Analysis and interpretation of data: $\mathrm{AD}$ and KS; Drafting the article: $\mathrm{AD}$ and KS; Revising it critically for important intellectual content: $\mathrm{AD}$ and KS; Approved final version of the manuscript: $\mathrm{AD}$ and $\mathrm{KS}$.

Conflict of Interest: The authors declare that they have no conflict of interest.

Funding: This work has been fully funded by Croatian Science Foundation (grant number 3553 awarded to the first author).

\section{References}

1. Gassó AM, Klettke B, Agustina JR, Montiel I. Sexting, mental health, and victimization among adolescents: A literature review. Int J Environ Res Public Health.2019;16(13):2364. https://doi.org/10.3390/ijerph 16132364.

2. Kosenko K, Luurs G, Binder AR. (2017). Sexting and sexual behavior 2011-2015: A critical review and metaanalysis of a growing literature. J Comput-Mediat Comm. 2017;22:141-60. https://doi.org/10.1111/jcc4.12187.

3. Muncaster L, Ohlsson I. Sexting: predictive and protective factors for its perpetration and victimization. J Sex Ag- 
gress. 2019;26(1):1-13. https://doi.org/10.1080/1355260 0.2019 .1645220 .

4. Sesar K, Dodaj A. Sexting: The exchange of sexually explicit content. Mostar: University of Mostar; 2020.

5. Ngo F, Jaishankar K. \& Agustina JR. Sexting: Current research gaps and legislative issues. Int J Cyber Criminol. 2017;11(2):161-8.

6. Temple JR, Choi H. Longitudinal association between teen sexting and sexual behavior. Pediatrics. 2014;134(5):e1287-e92. https://doi.org/10.1542/peds.2014 -1974 .

7. Wolak J, Finkelhor D, Mitchell KJ. How often are teens arrested for sexting? Data from a national sample of police cases. Pediatrics. 2012;129:4-12. https://doi.org/10.1542/ peds.2011-2242.

8. Wolak J, Finkelhor D. Sexting: a typology. Durham, NC: Crimes Against ChildrenResearch Center; 2011. [cited 2021 June 9]. Available at: www.unh.edu/ccrc/pdf/CV231_ Sexting\% 20Typology\%20Bulletin_4-6-11_revised.pdf.

9. Dodaj A, Sesar K. Sexting categories. Mediterr J Clin Psychol. 2020;8(2):1-26. https://doi.org/10.6092/2282$1619 /$ mjcp-2432.

10. Schmitz S, Siry L. Teenage folly or child abuse? State responses to 'sexting' by minors in the U.S. and Germany. Policy Int. 2011;3(2): 25-50. 2. https://doi.org/10.2202/ 1944-2866.1127.

11. Hudson HK, Marshall A. Consequences and predictors of sexting among selected southern undergraduates. Int J SexHealth. 2018;38:20-27. https://doi.org/10.1080/1931 7611.2017 .1404540 .

12. Mitchell KJ, Finkelhor D, Jones LM, Wolak J. Prevalence and characteristics of youth sexting: A national study. Pediatr. 2012;129(1):13-20. https://doi.org/10.1542/peds. 2011-1730.

13. Hasinoff AA. Sexting as media production: Rethinking social media and sexuality. New Media Soc. 2013;15(4):44965. https://doi.org/:10.1177/1461444812459171.

14. Kopecky K. Cyberbullying and other risks of internet communication focused on university students. Procedia Soc Behv. 2014;112(7):260-69. https://doi.org/:10.1016/j.sbspro.2014.01.1163.

15. Walker S, Sanci L, Temple-Smith M. Sexting: Young women's and men's views on its nature and origins. Journal of Adolescent Health. 2013;52(6):697-701. https://doi. org/:10.1016/j.jadohealth.2013.01.026.

16. Sesar K, Dodaj A, Šimić N. Motivational determinants of sexting: Towards a model integrating the research. Psychological Topics. 2019;28(3):461-82. https://doi.org/10. 31820/pt.28.3.1.
17. Bronfenbrenner, U. The ecology of human development - Experiments by nature and design. Harvard: Harvard University Press; 1979.

18. Cross D, Barnes A, Papageorgiou A, Hadwen K, Hearn L, Lester L. A social-ecological framework for understanding and reducing cyberbullying behaviours. Aggress Violent Behav. 2015;23:109-17. https://doi.org/10.1016/j. avb.2015.05.016.

19. Grant MJ, Bootht A. A typology of reviews: an analysis of 14 review types and associated methodologies. Health Infor Libr J. 2009;26(2):91-108. https://doi.org/10.1111/ j.1471-1842.2009.00848.x.

20. Strassberg DS, McKinnon RK, Sustaita MA, Rullo J. Sexting by high school students: An exploratory and descriptive study. Arch Sex Behav. 2013;42(1):15-21. https://doi. org/10.1007/s10508-012-9969-8.

21. Walker S, Sanci L, Temple-Smith M. Sexting: Young women's and men's views on its nature and origins. J Adolesc Health. 2013;52(6):697-701. https://doi.org/10.1016/j. jadohealth.2013.01.026.

22. Beckmeyer JJ, Herbenick D, Fu TC, Dodge B, Reece M, Fortenberry JD. Characteristics of adolescent sexting: Results from the 2015 National survey of sexual health and behavior. J Sex Marital Ther. 2019;45(8):767-80. https:// doi.org/10.1080/0092623X.2019.1613463.

23. Madigan S, Ly A, Rash CL, Van Ouytsel J, Temple JR. Prevalence of multiple forms of sexting behavior among youth: A systematic review and metaanalysis. JAMA Pediatrics. 2018;172(4):327-35. https://doi.org/10.1001/ jamapediatrics.2017.5314.

24. Lippman JR, Campbell SW. Damned if you do, damned if you don't ... if you're a girl: Relational and normative contexts of adolescent sexting in the United States. J Child Media. 2014;8(4):371-86. https://doi.org/10.1080/1748 2798.2014.923009.

25. Ringrose J, Harvey L, Gill R, Livingstone S. Teen girls, sexual double standards and 'sexting': Gendered value in digital image exchange. Fem Theory. 2013;14(3): 305-23. https://doi.org/10.1177/1464700113499853.

26. Dake JA, Price DH, Maziarz L, Ward B. Prevalence and correlates of sexting behaviour in adolescents. Am J Sex Educ. 2012;7(1):1-15. https://doi.org/10.1080/1554612 8.2012.650959.

27. Klettke B, Hallford DJ, Mellor DJ. Sexting prevalence and correlates: A systematic literature review. Clin Psychol Rev. 2014;34(1):44-53. https://doi.org/10.1016/j. cpr.2013.10.007.

28. Mitchell K, Finkelhor D, Jones L, Wolak J. Prevalence and characteristics of youth sexting: A national study. 
Pediatrics. 2012;129(1):13-20. https://doi.org/10.1542/ peds.2011-1730.

29. Houck CD, Barker D, Rizzo C, Hancock E, Norton A, Brown LK. Sexting and sexual behavior in at-risk adolescents. Pediatrics. 2014;133(2):276-82. https://doi. org/10.1542/peds.2013-1157.

30. Sesar K, Dodaj A. Sexting and emotional regulation strategies among young adults. Mediterr J Clin Psychol. 2019;7(1):125. https://doi.org/10.6092/2282-1619/2019.7.2008.

31. Trub L, Starks TJ. Texting under the influence: Emotional regulation as a moderator of the association between binge drinking and drunk texting. Cyberpsychology Behav Soc Netw. 2017;20(1):3-9. https://doi.org/10.1089/cyber.2016.0468.

32. Benotsch EG, Snipes DJ, Martin AM, Bull SS. Sexting, substance use, and sexual risk behavior in young adults. J Adolesc Health. 2013;52(3):307-13. https://doi.org/10. 1016/j. jadohealth.2012.06.011.

33. Crimmins DM, Seigfried-Spellar K. Peer attachment, sexual experiences, and risky online behaviors as predictors of sexting behaviors among undergraduate students. Comput Hum Behav. 2014;32:268-75. https://doi.org/10.1016/j. chb.2013.12.012.

34. Dir AL, Cyders MA, Coskunpinar A. From the bar to the bed via mobile phone: a first test of the role of problematic alcohol use, sexting, and impulsivity-related traits in sexual hookups. Comput Hum Behav. 2013;29(4):166470. https://doi.org/10.1016/j. chb.2013.01.039.

35. Yeung TH, Horyniak DR, Vella AM, Hellard ME, Lim MS. (2014). Prevalence, correlates and attitudes towards sexting among young people in Melbourne, Australia. Sex Health. 2014;11(4):332-40. https://doi.org/10.1071/ SH14032.

36. Ferguson CJ. Sexting behaviors among young Hispanic women: Incidence and association with other high-risk sexual behaviors. Psychiatric Q. 2011;82(3):239-43. https://doi.org/10.1007/s11126-010-9165-8.

37. Lee CH, Moak S, Walker JT. Effects of self-control, social control, and social learning on sexting behavior among South Korean youths. Youth Soc. 2013;48(2):242-64. https://doi.org/10.1177/0044118X13490762.

38. Perkins AB, Becker JV, Tehee M, Mackelprang E. Sexting behaviors among college students: cause for concern? Int J Sex Health. 2013;26(2):79-92. https://doi.org/10.1080/1 9317611.2013 .841792 .

39. Temple JR, Donna Le V, van den Berg P, Ling Y, Paul JA, Temple BW. (2014). Brief report: Teen sexting and psychosocial health. J Adolesc. 2014;37(1):33-6. https://doi. org/10.1016/j.adolescence.2013.10.008.
40. Baumgartner SE. (2013). Adolescent sexual risk behavior on the internet. Amsterdam School of Communication Research. 2013. [cited 2021 June 21] Available from: https://hdl.handle.net/11245/1.394024.

41. Scholes-Balog K, Francke N, Hemphill S. (2016). Relationships between sexting, self-esteem, and sensation seeking among Australian young adults. Sexualization, Media, \& Society, 2(2). https://doi. org/10.1177/2374623815627790.

42. Van Ouytsel J, Van Gool E, Ponnet K, Walrave M. Brief report: The association between adolescents' characteristics and engagement in sexting. J Adolesc. 2014;37(8):138791. https://doi.org/10.1016/j.adolescence.2014.10.004.

43. Delevi R, Weisskirch RS. Personality factors as predictors of sexting. Comput Hum Behav. 2013;29(6):2589-94. https://doi.org/10.1016/j.chb.2013.06.003.

44. Alonso C, Romero E. Sexting behaviours in adolescents: Personality predictors and psychosocial outcomes in a oneyear follow-up. An Psicol. 2019;35:214-24. https://doi. org/10.6018/analesps.35.2.339831.

45. Gámez-Guadix M, De Santisteban P. "Sex pics?”: Longitudinal predictors of sexting among adolescents. J Adolesc Health. 2018;63(5):608-14. https://doi.org/10.1016/j. jadohealth.2018.05.032.

46. Gámez-Guadix M, Santisteban P, Resett S. Sexting among Spanish adolescents: Prevalence and personality profiles. Psicothema. 2017;29(1):29-34. https://doi.org/10.7334/ psicothema2016.222.

47. Olatunde O, Balogun F. Sexting: Prevalence, predictors, and associated sexual risk behaviors among postsecondary school young people in Ibadan, Nigeria. Front Public Health. 2017;5:96. https://doi.org/10.3389/ fpubh.2017.00096.

48. Burić J, Garcia JR, Štulhofer A. Is sexting bad for adolescent girls' psychological well-being? A longitudinal assessment in middle to late adolescence. New Media Soc. 2020;1-20. https://doi.org/10.1177/1461444820931091.

49. Dodaj A, Sesar K, Cvitković M. Sexting and emotional difficulties in high school pupils. IJARP. 2019;6(1):1-16. http://dx.doi.org/10.6007/IJARP/v6-i1/6282.

50. Dodaj A, Sesar K, Jerinić S. A prospective study of highschool adolescent sexting behavior and psychological distress. J Psychol: Interdiscip Appl. 2019;154(2):111-28. https://doi.org/10.1080/00223980.2019.1666788.

51. Drouin M, Ross J, Tobin E. Sexting: a new, digital vehicle for intimate partner aggression? Comput Hum Behav. 2015;50(1):197-204. https://doi.org/10.1016/j. chb.2015.04.001. 
52. Frankel AS, Bauerle Bass S, Patterson F, Dai T, Brown D. Sexting, risk behavior, and mental health in adolescents: An examination of 2015 Pennsylvania youth risk behavior survey data. J School Health. 2018;88(3):190-9. https:// doi.org/10.1111/josh.12596.

53. Medrano JLJ, Lopez Rosales F, Gámez-Guadix M. Assessing the links of sexting, cybervictimization, depression, and suicidal ideation among university students. Arch Suicide Res. 2018;22(1):153-64. https://doi.org/10.1080/13 811118.2017 .1304304$.

54. Ševčíková A. Girls' and boys' experience with teen sexting in early and late adolescence. J Adolesc. 2016;51:156-62. https://doi.org/10.1016/j.adolescence.2016.06.007.

55. Ybarra M, Mitchell KJ. 'Sexting' and its relation to sexual activity and sexual risk behavior in a national survey of adolescents. J Adolesc Health. 2014;55(6):757-64. https:// doi.org/10.1016/j.jadohealth.2014.07.012.

56. Chalfen R. It's only a picture': Sexting, 'smutty' snapshots and felony charges. Vis Stud. 2009;24(3):258-68. https:// doi.org/10.1080/14725860903309203.

57. Van Ouytsel J, Ponnet K, Walrave M, d'Haenens L. Adolescent sexting from a social learning perspective. Telemat Inform. 2017;34(1):287-98. https://doi.org/10.1016/j. tele.2016.05.009.

58. Walrave M, Ponnet K, Van Ouytsel J, Van Gool E, Heirman W, Verbeek A. Whether or not to engage in sexting: Explaining adolescent sexting behaviour by applying the prototype willingness model. Telemat Inform. 2015;32(4):796-808. https://doi.org/10.1016/j. tele.2015.03.008.

59. Bianchi D, Morelli M, Baiocco R, Cattelino E, Laghi F, Chirumbolo A. Family functioning patterns predict teenage girls' sexting. Int J Behav Dev. 2019;43(6):507-14. https://doi.org/10.1177/0165025419873037.

60. Norman JM. (2017). Implications of parenting behaviour and adolescent attachment for understanding adolescent sexting. University of Windsor. 2017. [cited 2021 June 1]. Available from: https://scholar.uwindsor.ca/etd/7285/.

61. Campbell SW, Park YJ. Predictors of mobile sexting among teens: Toward a new explanatory framework. Mob Media Commun. 2014;2(1):20-39. https://doi. org/10.1177/2050157913502645.

62. West J, Lister C, Hall P, Crookston B, Snow P, Zvietcovich $\mathrm{M}$, et al. Sexting among Peruvian adolescents. BMC Pub Health. 2014;14:1-7. https://doi.org/10.1186/14712458-14-811.

63. Tomić I, Burić J, Štulhofer A. Associations between Croatian adolescents' use of sexually explicit material and sexual behavior: does parental monitoring play a role? Arch
Sex Behav. 2018;47(6):1881-93. https://doi.org/10.1007/ s10508-017-1097-z.

64. Dolev-Cohen M, Ricon T. Demystifying sexting: Adolescent sexting and its associations with parenting styles and sense of parental social control in Israel. Cyberpsychology. 2020;14(1):6. https://doi.org/10.5817/CP2020-1-6.

65. Lenhart A. Teens and sexting: How and why minor teens are sending sexually suggestive nude or nearly nude images via text messaging. Pew Research Center: Internet \& Technology. 2009. [cited 2021 June 2]. Available from: https://www.pewresearch.org/internet/2009/12/15/teensand-sexting/.

66. Hudson HK, Fetro JV. Sextual activity: predictors of sexting behaviors and intentions to sext among selected undergraduate students. Comput Hum Behav. 2015;49:61522. https://doi.org/10.1016/j.chb.2015.03.048.

67. Walrave M, Heirman W, Hallam L. Under pressure to sext? Applying the theory of planned behaviour to adolescent sexting. Behav Inf Technol. 2014;33(1): 86-98. https://doi.org/10.1080/0144929x.2013.837099.

68. Maheux AJ, Evans R, Widman L, Nesi J, Prinstein MJ, Choukas-Bradley S. Popular peer norms and adolescent sexting behavior. J Adolesc. 2020;78:62-6. https://doi. org/10.1016/j.adolescence.2019.12.002.

69. Valido A, Espelage DL, Hong JS, Rivas-Koehl M, Robinson, LE. Social-ecological examination of non-consensual sexting perpetration among U.S. adolescents. Int J Environ Res Pu. 2020;17(24):9477. https://doi.org/10.3390/ ijerph17249477.

70. Rovis D, Bezinović P, Bašić J. Interactions of school bonding, disturbed family relationships, and risk behaviors among adolescents. J Sch Health. 2015;85(10):671-79. https://doi.org/10.1111/josh.12296.

71. McNeely C, Falci C. School connectedness and the transition into and out of health-risk behavior among adolescents: A comparison of social belonging and teacher support. J Sch Health. 2004;74(7):284-92. https://doi. org/10.1111/j.1746-1561.2004.tb08285.x.

72. Handebo S, Kebede Y, Morankar SN. Does social connectedness influence risky sexual behaviours? Finding from Ethiopian youths. Int J Adolesc Youth. 2018;23(2):14558. https://doi.org/10.1080/02673843.2017.1306448.

73. Hunter SC, Russell K, Pagani S, Munro L, Pimenta SM, Marín-López I, Hong JS, Knifton L A social-ecological approach to understanding adolescent sexting behavior. Arch Sex Behav. 2021;50:2347-57. https://doi.org/10.1007/ s10508-021-01988-9.

74. King KA, Vidourek RA, Davis B, McClellan W.Increasing self-esteem and school connectedness through a multidimensional mentoring program. J School Health. 
2002;72(7):294-9. https://doi.org/10.1111/j.1746-1561. 2002.tb01336.x

75. Walrave M, Heirman W, Hallam L. Under pressure to sext? Applying the theory of planned behaviour to adolescent sexting. Behav Inf Technol. 2014;33(1):86-98. https://doi.org/10.1080/0144929x.2013.837099.

76. O'Keefe GS, Clarke-Pearson K, Council on Communications and Media. The impact of social media on children, adolescents, and families. Pediatrics. 2011;127(4):800-4. https://doi.org/10.1542/peds.2011-0054.

77. Dilberto GM, Mattey E. Sexting: Just how much of a danger is it and what can school nurses do about it? NASN Sch Nurse. 2009;24(6):262-7. https://doi. org/10.1177/1942602X09348652.

78. Limber SP, Nation M, Tracy AJ, Melton GB, Flerx V. (2004). Implementation of the Oweus bullying prevention program in the Southeastern United States. In: Smith PK, Pepler D, Rigby, editors. Bullying in schools: How successful can interventions be? Cambridge: Cambridge University Press;2004. p 55-79.

79. Theodore S. Integrated response to sexting: utilization of parents and schools in deterrence. J Contemp Health Law Policy. 2010;27(2):365.

80. Jones, TM,Hillier, L.Sexuality education school policy for Australian GLBTIQ students. Sex Educ.2012;12(4): $437-$ 54. https://doi.org/10.1080/14681811.2012.677211.

81. Burén J. Sexting among adolescents. Sweden: University of Gothenburg; 2018.

82. Lottes IL, Alkula, T. An investigation of sexuality-related attitudinal patterns and characteristics related to those patterns for 32 European countries. Sex Res Soc Policy.2011;8:77-92. https://doi.org/10.1007/s13178-0110038-1.

83. Dobson AS,Ringrose J. (2016). Sext education: pedagogies of sex, gender and shame in the schoolyards of Tagged and Exposed. Sex Educ.2016;16(1):8-21. https://doi.org/ 10.1080/14681811.2015.1050486.

84. Salter M, Crofts T, Lee M. Beyond criminalisation and responsibilisation: Sexting, gender and young people. Curr Issues Crim Justice.2013;24(3):301-16. https://doi.org/10 $.1080 / 10345329.2013 .12035963$.

85. Jørgensen C, Weckesser A, Turner J, Alex W. Young People's views on sexting education and support needs: Findings and recommendations from a UK-based study', Sex Educ.2018;19(1):25-40. https://doi.org/10.1080/146818 11.2018.1475283.

86. Crofts T, Lee M, McGovern A, Milivojevic S. Sexting and young people. Basingstoke: Palgrave McMillan; 2015.
87. Ringrose J, Gill R, Livingstone S, Harvey L. (2012). A qualitative study of children, young people and 'sexting': A report prepared for the NSPCC. National Society for the Prevention of Cruelty to Children Report. Retrieved from: http://eprints.lse.ac.uk/44216/1/__Libfile_repository_ Content_Livingstone $\% 2$ C $\% 20$ S_A\%20qualitative $\% 20$ study $\% 20$ of $\% 20$ children $\% 2 \mathrm{C} \% 20$ young $\% 20$ people $\% 20$ and $\% 20 \% 27$ sexting $\% 27 \% 20 \% 28 \mathrm{LSE} \% 20 \mathrm{RO} \% 29$.pdf.

88. Dodaj A, Sesar K. Sexting categories. Mediterr J Clin Psychol. 2020;8(2):1-26. https://doi.org/10.6092/2282$1619 /$ mjcp-2432.

89. Strohmaier H, Murphy M, DeMatteo D. Youth sexting: Prevalence rates, driving motivations, and the deterrent effect of legal consequences. Sex Res Social Policy.2014;11(3):245-55. https://doi.org/10.1007/s13178014-0162-9.

90. Temple-Smith M, Moore SM, Rosenthal DA. Sexuality in adolescence: The digital generation. Routledge/Taylor \& Francis Group; 2016.

91. Crawford M, Popp D. Sexual double standards: A review and methodological critique of two decades of research. J Sex Res.2003;40(1):13-26. https://doi.org/10.1080/ 00224490309552163.

92. Martel LD, Hawks S, Hatfield E. Sexual behavior and culture. In: Spielberger C. Encyclopedia of Applied Psychology. London: Elsevier; 2004. p 385-92.

93. 93.Allison R, Risman BJ. A double standard for "hooking up": How far have we come toward gender equality? Soc Sci Res.2013;42(5):1191-206. https://doi.org/10.1016/j. ssresearch.2013.04.006.

94. Kreager DA, Staff J, Gauthier R, Lefkowitz ES, Feinberg ME. The double standard at sexual debut: Gender, sexual behavior and adolescent peer acceptance. Sex roles.2016;75(7-8):377-92.https://doi.org/10.1007/s11199 -016-0618-x.

95. Marganski A. Sexting in Poland and the United States: A comparative study of personal and social-situational factors. Int J Cyber Criminol. 2017:11(2):183-201. https:// doi.org/10.5281/zenodo.1037385.

96. Morelli M, Chirumbolo A, Bianchi D, Baiocco R, Cattelino E, Laghi F, et al. The role of HEXACO personality traits in different kinds of sexting: A cross-cultural study in 10 countries. Comput Hum Behav. 2020;113:106502. https://doi.org/10.1016/j.chb.2020.106502.

97. Wood M, Barter C, Stanley N, Aghtaie N, Larkins C. Images across Europe: The sending and receiving of sexual images and associations with interpersonal violence in young people's relationships. Child Youth Serv Rev. 2015;59:14960. https://doi.org/10.1016/j.childyouth.2015.11.005. 
98. Baumgartner SE, Sumter SR, Peter J, Valkenburg PM, Livingstone S. Does country context matter? Investigating the predictors of teen sexting across Europe. Comput Hum Behav. 2014;34:157-64. https://doi.org/10.1016/j. chb.2014.01.041.

99. National Campaign to Prevent Teen and Unplanned Pregnancy. (2008). Sex and Tech: Results from a survey of teens and young adults. Retrieved from: https://thenationalcampaign.org (10.2.2021.).
100. Abraham AE. Sexting uncensored: an exploratory study of the behaviors, experiences and perceptions of sexting among college students [master thesis]. Fresno: California State University; 2015.

101. Crimmins DM, Seigfried-Spellar KC. Adults who sext: Exploring differences in self-esteem, moral foundations, and personality. Int J Cyber Criminol.2017;11(2):169-82. https://doi.org/10.5281/zenodo.1037379. 